Original Article

\title{
Endoscopic posterior nasal neurectomy in persistent allergic rhinitis: a clinical study
}

\author{
Ahmed I. Zaghloul ${ }^{1}$ \\ ${ }^{1}$ Otorhinolaryngology Department, Damietta Faculty of Medicine, Damietta, Al-Azhar University, Egypt
}

\begin{abstract}
A B S T R A C T
Background: In the last decades, incidence of allergic rhinitis (AR) showed steadily increase in developed and developing countries; with profound effects on patient life and overall health care system. In intractable AR, endoscopic neurectomy of posterior nasal nerve had been introduced as a curative alternative. However, its efficacy and safety not adequately addressed.
\end{abstract}

Objective: The current study aimed to present our clinical experience with endoscopic posterior nasal neurectomy [safety and efficacy] and to address its effect on the patient quality of life.

Methodology: A sixty-three patients with AR were included. Clinical symptoms of AR had been assessed before and at 3, 6 and 12 months after surgery using a numerical score. In addition, patients had been asked to fill a 28 -items rhinoconjunctivitis quality of life (RQoL) questionnaire.

Results: There was progressive and significant improvement of clinical symptoms and improvement of the RQoL scores after surgery when compared to preoperative values. All scores reduced significantly at 3 months with subsequent reduction at 6 months which become stable to the end of the first year, except quality of life which showed another significant reduction at the end of the first year when compared to values at the $6^{\text {th }}$ postoperative month. No major complications had been recorded, and the overall successful control on nasal symptoms had been recorded for $68.3 \%, 81.0 \%, 88.9 \%$ and $79.4 \%$ for sneezing, itching, rhinorrhea and nasal obstruction, respectively.

Conclusion: Endoscopic posterior nasal neurectomy is an effective and safe surgical technique for treatment of AR resistant to medical therapy.

JRAM 2020; 2 (1): 87-92

Keywords: Allergic rhinitis; Intractable; Neurectomy; Posterior Nasal Nerve; Quality of Life.

Submission Date: 1 September 2020

Acceptance Date: 7 October 2020.

Corresponding author: Corresponding author: Ahmed Ibrahim Zaghloul, otorhinolaryngology department, Damietta faculty of medicine, Damietta, Al-Azhar University, Egypt. Tel: 01007401948. Email: Zaghloul.ent@ domazhermedicine.edu.eg

Please cite this article as: Zaghloul AI. Endoscopic posterior nasal neurectomy in persistent allergic rhinitis: a clinical study. JRAM 2020; 2 (1): 87-92. DOI: 10.21608/jram.2020.41456.1081

\section{INTRODUCTION}

Allergic rhinitis (AR) is a growing health problem all over the world. Around the world, more than 500million subjects complained of AR, and its prevalence had been increased during the last decades ${ }^{[1,2]}$. AR affected approximately 113 million people in Europe and about $30-60$ million in the United States ${ }^{[3,4]}$.

Poorly controlled symptoms of AR could lead to different comorbidities (e.g., impaired sleep with consequent daytime fatigue which affect overall patient's work or school achievement; all affect quality of life (QoL) with increased treatment costs) ${ }^{[5,6]}$.

The ideal treatment strategy of AR includes complete avoidance of allergens, local corticosteroids, leukotriene receptor antagonists, Th2 cytokine suppressors and nasal antihistamines, therapy.

https://jram.journals.ekb.eg

Print ISSN 2636-252X - Online ISSN 2636-2538
However, these therapeutic interventions show limited effectiveness and high cost of long-term treatment ${ }^{[3]}$.

Allergic rhinitis resistant to drug therapy usually submitted to posterior nasal nerve resection. This surgical maneuver was originated from Vidian neurectomy, which markedly reduces hypersecretion and hypersensitivity by ablation of the Vidian nerve with a transantral approach. However, Vidian neurectomy is occasionally accompanied by permanent comorbidities [e.g., reduced lacrimation and development of upper lip numbness] ${ }^{[7]}$. Posterior nasal neurectomy is a novel alternative technique in which neural bundles - under direct vision- are selectively cut or cauterized at the sphenopalatine foramen. This enables avoidance of surgical Personal non-commercial use only. JRAM copyright @ 2020. All rights reserved 
compilations especially reduced lacrimation. However, literature is not yet addressed its safety and efficacy and no final consensus or guidelines had been drawn. In addition, it is of most importance to present our clinical experience and share our results regarding such procedure with the scientific community ${ }^{[8]}$. The aim of this work was to present our clinical experience with endoscopic posterior nasal neurectomy in persistent allergic rhinitis.

\section{PATIENTS AND METHODS}

We included sixty-three patients underwent surgery for insurmountable AR between June 2018 and June 2019 at Al-Azhar University Hospital (Damietta). Subjective symptoms were evaluated before and after surgery. The subjective symptoms included sneezing, itching, rhinorrhea and nasal blockage had been assessed by a questionnaire using a numerical score based on Okuda's system ${ }^{[9]}$, each symptom was scored on a scale of $0-4$ ( 0 , none; 1 , mild; 2 , moderate; 3 , severe; and 4, very severe). The patients filled the questionnaire at 3, 6 and 12 months postoperatively. Complications had been addressed after surgery was also documented.

Quality of life (QoL) had been assessed in pre-and postoperative periods by the widely used, rhinoconjunctivitis quality of life (RQoL) scale. It formed from 28 questions (adult form), divided into seven domains (limitation of activity, sleep-related problems, nasal symptoms, symptoms of the eye, symptoms not related to eye or nose, practical problems and emotional state). Of importance, the questionnaire contains three 'patient-specific' questions in the domain of activity that permits the selection of the most limited three activities by their condition. Patients had been instructed to express the effect of their rhinoconjunctivitis during the previous week, through the answer to each question on a sevenpoint scale ( 0 for no impairment at all and 6 for severe impairment). The overall score represented by the mean of all 28 questions ${ }^{[10]}$.

Preoperatively, the patients were informed about the surgical procedures, signed an informed consent, and then underwent trans-nasal resection of posterior nasal nerve [TRPN] under general anesthesia. All patients were followed-up in our outpatient clinic for 12 months postoperatively. Due to COVID-19 pandemic, patients continued follow up after March 2020, were checked by telephone and filled the questionnaire in an electronic form.

Surgical technique: This procedure had been completed under general anesthesia. A $0^{0}$ or a $30^{\circ}$ nasal endoscope with a diameter of $4 \mathrm{~mm}$ is used throughout the surgery. About $1 \mathrm{~mL}$ of 1:100,000 epinephrine was injected at the posterior end of the middle meatus. Opening of the maxillary sinus and identification of its ostium to take it as a guide to reach the sphenopalatin foramen. Then in the middle meatus, a curved incision, $1.5 \mathrm{~cm}$ long, had been made, starting from the superior margin of the inferior nasal turbinate up to the horizontal part of the ground lamella of the middle turbinate. The dissected mucosal flap had been separated from the vertical plate of the palatine bone, and the flap had been folded backwards until exposure of the sphenopalatine notch and the superior margin of the vertical plate of the palatine bone. Then, at the level of sphenopalatine foramen, the neurovascular bundle had been identified, with inclusion of the posterior nasal nerve. The PNN had identified and sectioned from the sphenopalatine artery only in four cases. The rest of cases, the whole bundle had been sectioned including the artery there is no significant side effects between both maneuvers. To avoid postoperative bleeding, a sufficient coagulation had been applied and nasal packing was inserted for 2 days.

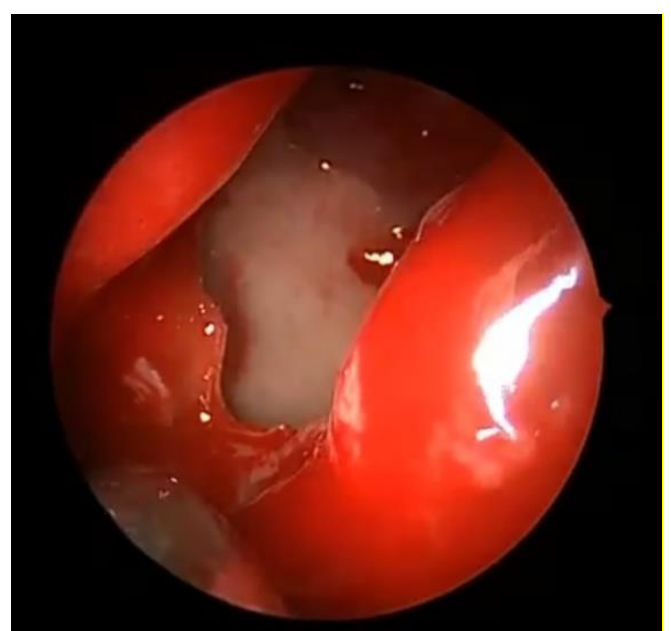

Figure (1): Photo shows the left side nasal cavity with opening of the maxillary sinus

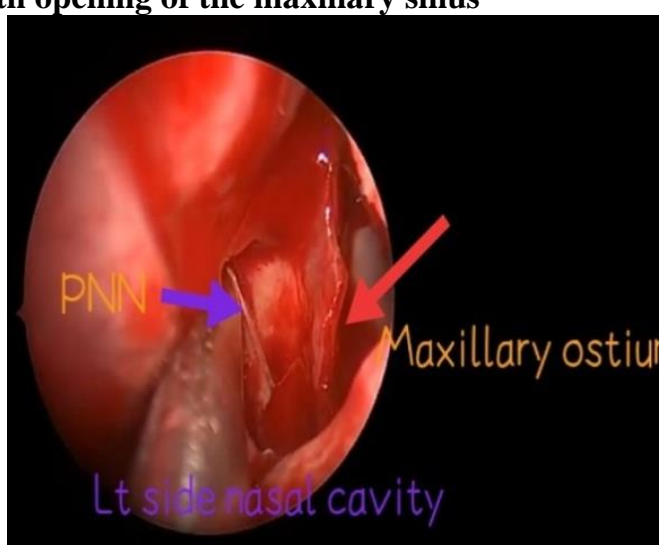

Figure (2): Photo shows, the dissected mucosal flap had been separated from the vertical plate of the palatine PNN was showed and the maxillary ostim

\section{Statistical analysis of data}

Numerical data presented as arithmetic mean \pm standard deviation (SD), while categorical variables presented as relative frequency (n.) and percentages (\%). Repeated measure (ANOVA; analysis of variance) had been used to examine the effect over time (at different (multiple) points of time), while paired $(\mathrm{t})$ test was used to examine the statistical difference between two points of time. $\mathrm{P}$ value $<0.05$ considered the margin of significance to interpret results. 


\section{RESULTS}

A total of 63 patients satisfactorily completed the surgical procedure. Table (1) presented patient demographics, mean preoperative symptoms scores and preoperative rhino-conjunctivitis quality of life [RQoL] score. Patient's age ranged between 17 and 44 years, the mean age $\pm \mathrm{SD}(28.02 \pm 5.43$ years). Males represented most patients $(60.3 \%)$. Regarding outcome, there was progressive significant improve-ment of sneezing, itching, rhinorrhea, obstruction and RQoL from preoperative values towards the end of the follow up at 12 months postoperatively. All scores dropped significantly at 3 months postoperatively when compared to preoperative values, and at 6 months postoperative when compared to values at 3 months postoperative (Table 2). At 12 months of follow up, there was no significant difference in sneezing, itching, rhinorrhea and obstruction severity scores when compared to corresponding values at 6 months postoperatively. This indicated stabilization of response at 6 months. However, RQoL symptom score significantly decreased at 12 months when compared to corresponding values at 6 months $(0.60 \pm 0.52$ vs. $0.96 \pm 0.67$ respectively) (Table 3). No major complications were noted, specifically severe bleeding, significant pain atrophic rhinitis or persistent crusting. Temporary numbness of the lip, gingival mucosa and teeth had been observed in one patient, who completely recovered by one month (Table 4). At the period of the last visit, successful control of each nasal symptom (score 0 or 1) was observed in (68.3\%) patients for sneezing, (81.0\%) patients for itching, $(88.9 \%)$ for rhinorrhea and $(79.4 \%)$ patients for nasal obstruction (Table 5).

Table (1): Patient demographics, mean preoperative symptoms scores and preoperative rhino-conjunctivitis quality of life $[\mathrm{RQoL}]$ score

\begin{tabular}{|l|l|c|}
\hline Variable & & Statistics \\
\hline Age (year) & & $28.02 \pm 5.43 ; 17-44$ \\
\hline Sex (n, \%) & Male & $38(60.3 \%)$ \\
\hline & Female & $25(39.7 \%)$ \\
\hline & Sneezing & $3.57 \pm 0.49$ \\
\hline Preoperative & Itching & $3.49 \pm 0.50$ \\
symptoms score & Rhinorrhea & $3.31 \pm 0.47$ \\
& Obstruction & $3.39 \pm 0.49$ \\
\hline Preoperative RQoL score & $3.85 \pm 0.69$ \\
\hline
\end{tabular}

Table (2): The outcome among studied populations regarding symptom and quality of life scores

\begin{tabular}{|l|c|c|c|c|c|}
\hline Variable & Preoperative & Post-op 3m. & Post-op 6m. & Post-op 12m. & P value \\
\hline Sneezing & $3.57 \pm 0.49$ & $1.17 \pm 0.81^{\#}$ & $0.95 \pm 0.83^{¥}$ & $0.93 \pm 0.83$ & $0.001^{*}$ \\
\hline Itching & $3.49 \pm 0.50$ & $1.00 \pm 0.67^{\#}$ & $0.79 \pm 0.78^{¥}$ & $0.76 \pm 0.75$ & $0.001^{*}$ \\
\hline Rhinorrhea & $3.31 \pm 0.47$ & $1.13 \pm 0.75^{\#}$ & $0.96 \pm 0.71^{\ddagger}$ & $0.67 \pm 0.67$ & $0.001^{*}$ \\
\hline Obstruction & $3.39 \pm 0.49$ & $1.22 \pm 0.65^{\#}$ & $0.90 \pm 0.73^{¥}$ & $0.89 \pm 0.72$ & $0.001^{*}$ \\
\hline RQoL & $3.85 \pm 0.69$ & $\begin{array}{c}1.31 \pm 0.85^{\#} \\
\text { *: significant p palue }\end{array}$ & $0.96 \pm 0.67^{*}$ & $0.60 \pm 0.52$ & $0.001^{*}$ \\
\hline
\end{tabular}

Table (3): Comparison between 6- and 12-months values of symptom severity scores and quality of life score

\begin{tabular}{|l|c|c|c|c|}
\hline Variable & Post-op 6m. & Post-op 12m. & Paired (t) & P value \\
\hline Sneezing & $0.95 \pm 0.83$ & $0.93 \pm 0.83$ & 0.444 & 0.658 \\
\hline Itching & $0.79 \pm 0.78$ & $0.76 \pm 0.75$ & 1.426 & 0.159 \\
\hline Rhinorrhea & $0.96 \pm 0.71$ & $0.67 \pm 0.67$ & 1.426 & 0.159 \\
\hline Obstruction & $0.90 \pm 0.73$ & $0.89 \pm 0.72$ & 1.000 & 0.321 \\
\hline RQoL & $0.96 \pm 0.67$ & $\begin{array}{c}0.60 \pm 0.52 \\
\text { *: significant p value }\end{array}$ & 4.60 & $0.001 *$ \\
\hline
\end{tabular}

Table (4): Complications among studied populations

\begin{tabular}{|l|c|}
\hline Variable & Statistics \\
\hline Massive bleeding & $0(0.0 \%)$ \\
\hline Severe pain & $0(0.0 \%)$ \\
\hline Numbness & $1(1.6 \%)$ \\
\hline Atrophic rhinitis & $0(0.0 \%)$ \\
\hline Crustation & $0(0.0 \%)$ \\
\hline
\end{tabular}


Table (5): Successful control of nasal symptoms at the last visit

\begin{tabular}{|l|c|}
\hline Variable & Statistics \\
\hline Sneezing & $43(68.3 \%)$ \\
\hline Itching & $51(81.0 \%)$ \\
\hline Rhinorrhea & $56(88.9 \%)$ \\
\hline Obstruction & $50(79.4 \%)$ \\
\hline
\end{tabular}

\section{DISCUSSION}

Transnasal endoscopic neurectomy of the posterior nasal nerve is recognized as an effective intervention for the management of $\mathrm{AR}$ that did not respond to medical treatment. Its effectiveness is specifically valued for patients with severe rhinorrhea, due to interruption of parasympathetic nerve supply. Sneezing is also significantly reduced due to interruption of afferent sensory nerve fibers. The rationale behind PNN based on the pathogenic role played by neurogenic inflammation in AR ${ }^{[11]}$. In addition, an interaction between immune system and neural circuits of nervous system had been proposed in which both immunity system and nerve impulses triggered by and to control inflammation, with an introduction of new bridge between immunology and neuroscience ${ }^{[12]}$. The secretion of different neuropeptides could play a pathophysiological role in AR through modulation the immune and secretory function of the nasal mucosa.

The posterior nasal nerve is the dominant provider of parasympathetic, sympathetic, and sensory supply of the nasal respiratory mucosa. Thus, neurectomy prevents neural supply of nasal mucosa and seems to relieve and control manifestations of $\mathrm{AR}^{[13]}$.

Results of the current work are in line with Wang et al. ${ }^{[14]}$ who reported that, posterior nasal neurectomy is an effective treatment of sneezing and rhinorrhea associated with AR, without any intra-operative comorbidities. They confirmed their results by measurement of cytokines with significant reduction of different cytokines [neuropeptide-Y, substance-p, and interleukin-5] postoperatively. Their discovery of significant reduction of neuropeptides confirms the role of neuropeptides in the pathogenesis of AR. In addition, Ahilasamy and Dinesh [15] reported significant improving of nasal symptoms (sneezing and rhinorrhea) with no or mild complications (e.g., lip numbness and nasal adhesions). They explained lip numbness by electrocoagulation neurectomy at the site too close to the sphenopalatine foramen. Furthermore, Kobayashi et al. ${ }^{[16]}$ reported on the efficacy and safety of posterior nasal neurectomy in management of AR resistant to medical therapy. They ascribed its efficacy for treatment of rhinorrhea to suppression of nasal secretion by the interruption of parasympathetic nerve supply to nasal mucosa. Reduction of sneezing was due to interruption of sensory nerve fibers of PNN. Ikeda et al. ${ }^{[17]}$ performed PNN for 56 patients with resistant $\mathrm{AR}$ and non-AR and reported $80 \%$ reduction in total symptom score in $86.0 \%$ of patients. Ikeda et al. ${ }^{[18]}$ further confirmed the efficacy of PNN thought detection of significant reduction of the density of mucosal gland cells in histological sections; in addition to significant reduction of inflammatory cells. Additionally, Nishijima et al. [13] confirmed the efficacy (significant improvement of clinical manifestations) with low complication rate, but they addressed the problem of incomplete response after PNN. They explained this by gradual postoperative reinnervation or the presence of accessory secretory fibers to the posterolateral nasal mucosa that escape the passage through sphenopalatine foramen ${ }^{[19]}$. This could explain the results of the current work, where the complete control of symptoms (success rate) revealed variable percentages for each symptom $(68.3 \%, 81.0 \%$, $88.9 \%$, and $79.4 \%$ for sneezing, itching, rhinorrhea and obstruction, respectively).

An important aspect of the current work is the assessment of the quality of life related to AR, as Tantilipikorn et al. ${ }^{[20]}$ reported that, AR impair patient quality of life due to nasal symptoms, mainly itching, sneezing, cough, nasal obstruction, postnasal drip and rhinorrhea. Other consequence of AR could include sleep related problems, tiredness through the day, poor concentration, and headache. All affect and limit their daily activities, patient become frustrated and irritable. Interestingly, results of the current work showed steadiness in symptoms scores after the $6^{\text {th }}$ months of PNN, but quality of life continue improvement till the end of the first year after surgery. Juniper et al. [21] reported that, patients with AR seeking treatment usually concentrates on the improvement of clinical symptoms that certainly improve their overall wellbeing and quality of life. They reported absence of correlation between symptoms severity and QoL and thus advocated the use of separate tool to assess QoL directly. We used RQoL questionnaire as it is available in Arabic version, previously validated, short, easy, and understood and self-administered with no significant burden either on the patient or the physician (at correction or data manipulation). Oz Doganoglu et al. ${ }^{[22]}$ demonstrated the increased acceptance of QoL assessment in the field of allergy and different field of clinical medicine. They valued the different QoL tools in $\mathrm{AR}$ and recommend their use as supportive outcome measurements in clinical trials and in daily care practices.

The measurement of QoL in the current study represented a strength point, while small number of studied patients and short duration of follow up represented limiting steps. Thus, future studies with longer duration of follow up are recommended. 


\section{CONCLUSION}

From the current study, we could conclude that, endoscopic posterior nasal neurectomy is an effective and safe intervention for treatment of AR resistant to medical therapy. It is associated with marked reduction of clinical nasal manifestations that significantly improves quality of life.

\section{Conflicts of interest}

Author declares no conflict of interest

Financial disclosure

Author declares that, the research completely financed by the author himself.

\section{REFERENCES}

1. Ma T, Wang X, Zhuang Y, Shi H, Ning H, Lan $\mathbf{T}$, et al. Prevalence and risk factors for allergic rhinitis in adults and children living in different grassland regions of Inner Mongolia. Allergy 2020; 75(1):234-239.

2. Brożek JL, Bousquet J, Agache I, Agarwal A, Bachert C, Bosnic-Anticevich S, et al. Allergic Rhinitis and its Impact on Asthma (ARIA) guidelines - 2016 Revision. J Allergy Clin Immunol 2017; 140(4):950.

3. Cox L. Approach to Patients with Allergic Rhinitis: Testing and Treatment. Med Clin N Am 2020; 104: 77-94.

4. Wallace DV, Dykewicz MS, Bernstein DI, Blessing-Moore J, Cox L, Khan DA, et al. The diagnosis and management of rhinitis: an updated practice parameter. J Allergy Clin Immunol 2008; 122: S1-84.

5. Minto H, Hogan AD. Allergic rhinitis is associated with otitis media with effusion: a birth cohort study. Pediatrics 2013; 132: S29-30.

6. Baena-Cagnani CE, Canonica GW, Zaky Helal M, Gómez RM, Compalati E, Zernotti ME, et al. The international survey on the management of allergic rhinitis by physicians and patients (ISMAR). World Allergy Organ J 2015; 8:10.

7. Li S, Cheng J, Yang J, Zhao Y, Zhu Z, Zhao C, Wang Z. Efficacy of posterior nasal neurectomy for allergic rhinitis combined with chronic rhinosinusitis with nasal polyps. Acta Otolaryngo. 2019; 139(10):890-894.

8. Kanaya T, Kohno N. Submucosal Inferior Turbinoplasty Using a New Continuous Suction Irrigation Method. Front Surg 2017; 8 (4):24.

9. Baba $\mathbf{S}$, Kon-no A, Takenaka $\mathbf{H}$, editors. Practical guideline for the management of allergic rhinitis in Japan. $6^{\text {th }}$ ed., Tokyo: Life Science Co. Ltd.; 2009. p. 18-31.
10. Juniper EF, Thompson AK, Ferrie PJ, Roberts J. Validation of the standardized version of the rhinoconjunctivitis quality of life questionnaire. J Allergy Clin Immunol 1999; 104: 364-369.

11. Klimek L, Pfaar O. Allergic rhinitis. Immunological and neurogenic mechanisms. Hno 2011; 59(12):1191-7.

12. Pavlov VA, Tracey KJ. Neural regulation of immunity: molecular mechanisms and clinical translation. Nat Neurosci 2017; 20(2):156-66.

13. Nishijima $\mathbf{H}$, Kondo $\mathbf{K}$, Toma-Hirano $M$, Kikuta S, Ando M, Ueha R, et al. Prolonged denervation induces remodeling of nasal mucosa in rat model of posterior nasal neurectomy. Int Forum Allergy Rhinol 2017; 7(7):670-8.

14. Wang L, Chen M, Xu M. Effect of posterior nasal neurectomy on the suppression of allergic rhinitis. Am J Otolaryngol 2020; 41(3):102410.

15. Ahilasamy N, Rajendran Dinesh K. Endoscopic posterior nasal neurectomy. J Laryngol Otol 2019:1-5.

16. Kobayashi T, Hyodo M, Nakamura $K$, Komobuchi H, Honda N. Resection of peripheral branches of the posterior nasal nerve compared to conventional posterior neurectomy in severe allergic rhinitis. Auris Nasus Larynx. 2012; 39(6):593-6.

17. Ikeda K, Oshima T, Suzuki M, Suzuki H, Shimomura A. Functional inferior turbinosurgery (FITS) for the treatment of resistant chronic rhinitis. Acta Otolaryngol 2006; 126(7):739-45.

18. Ikeda K, Yokoi H, Saito T, Kawano K, Yao T, Furukawa M. Effect of resection of the posterior nasal nerve on functional and morphological changes in the inferior turbinate mucosa. Acta Otolaryngol. 2008; 128(12):1337-41.

19. Bleier BS, Schlosser RJ. Endoscopic anatomy of the postganglionic pterygopalatine innervation of the posterolateral nasal mucosa. Int Forum Allergy Rhinol 2011; 1(2):113-7.

20. Tantilipikorn P, Saisombat P, Phonpornpaiboon P, Pinkaew B, Lermankul W, Bunnag C. Minimal clinically important difference for the rhinoconjunctivitis quality of life questionnaire in allergic rhinitis in Thai population. Asia Pac Allergy 2019; 22; 9(1) :e6.

21. Juniper EF, Thompson AK, Roberts JN. Can the standard gamble and rating scale be used to measure quality of life in rhinoconjunctivitis? Comparison with the RQLQ and SF-36. Allergy 2002; 57: 201-206.

22. Oz Doganoglu T, Songu M, Inancli HM. Quality of life in allergic rhinitis. Ther Adv Respir Dis 2012; 6(1):25-39. 


\section{الملخص العربي \\ استئصال العصب الأنفي الخلفي بالمنظار في حالات حساسية الأنف المستمرة: دراسة سريرية

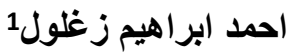 \\ 1قنم الانف و الاذن والحنجرة، كلية طب دمباط، دمباط، جامعة الازهر، جمهورية مصر العربية.}

ملخص البحث

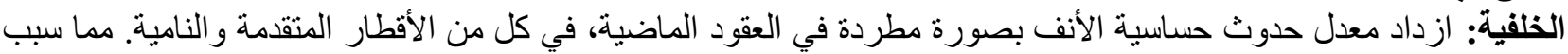

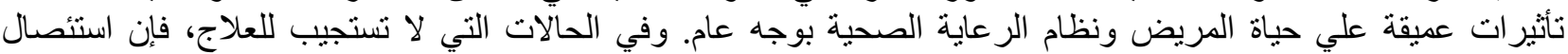

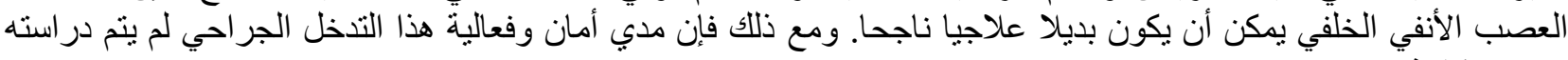
تصورة كافية. الهدف: تهدف الدراسة الحالية لعرض خبرة خبرتنا السريرية في استخدام المنظار لاسئصسال العصب الأنفي الخلفي من حيث مدي الأمان و الفاعلية، وتقييم تأثنيره علي جودة لئة حياة المريض.

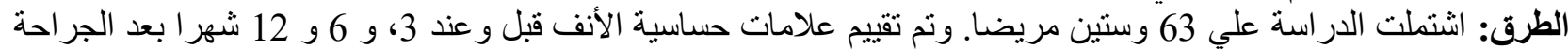

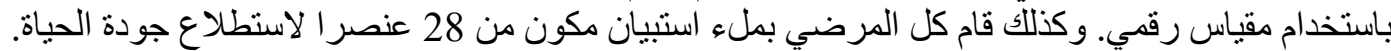

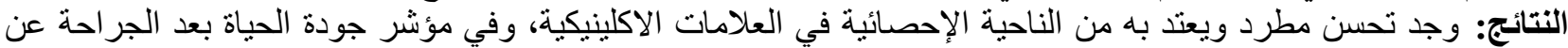

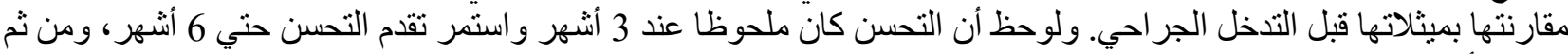

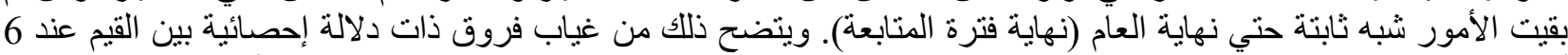

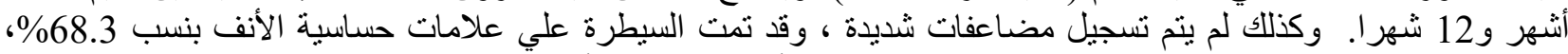

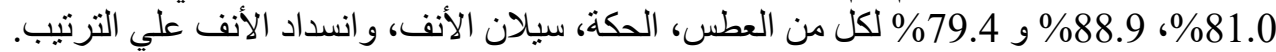

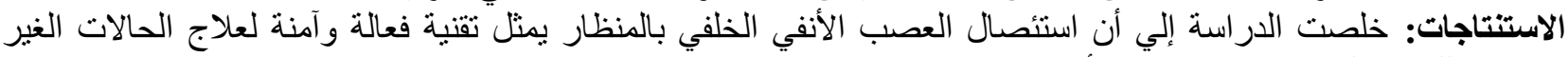

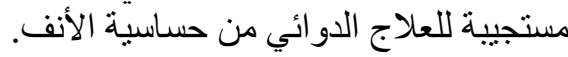

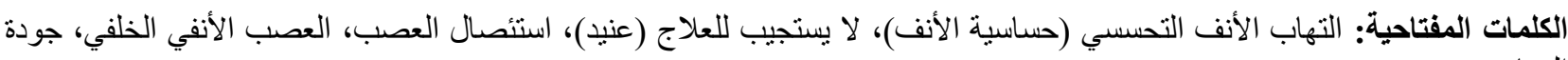
الحياة

الاسم: احمد ابر اهيم زغلول، قسم الانف والاذن و الحنجرة، كلية طب دمياط، دمياط، جامعة الأزهر، جمهورية مصر العربية.

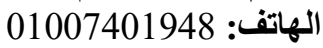
البريد الاككتروني:Zaghloul.ent@ domazhermedicine.edu.eg 